\title{
Synthesis and antifungal efficacy of 1,3,5-triazines
}

\author{
Viktor Milata $^{\text {a, b }}$, Ladislav Reinprecht ${ }^{\mathrm{c}}$, Juraj Kizlink ${ }^{\mathrm{d}}$ \\ ${ }^{a}$ Faculty of Chemical and Food Technology, STU Bratislava, \\ Radlinského 9, 81237 Bratislava, Slovakia \\ ${ }^{b}$ Faculty of Natural Sciences, University of SS Cyril and Methodius in Trnava, \\ nám. J. Herdu 2, SK-917 01 Trnava, Slovakia \\ ${ }^{c}$ Faculty of Wood Sciences and Technology, Technical University of Zvolen, \\ T. G. Masaryka 24, SK-960 53 Zvolen, Slovakia \\ ${ }^{d}$ Faculty of Chemistry, Brno University of Technology \\ Purkyňova 118, CZ-612 00 Brno, Czech Republic \\ viktor.milata@stuba.sk,reinpret@vsld.tuzvo.sk,kizlink@fch.vutbr.cz
}

\begin{abstract}
: 1,3,5-triazines with tree identical groups: benzotriazol-1/2-yl, imidazol-1-yl, pyrazolyl-1-yl, 3,5dimethylpyrazolyl-1-yl, 4,5-diphenylimidazol-1-yl， benzimidazolyl-1-yl，2-methylbenzimidazolyl-1-yl, or 2-phenylbenzimidazolyl-1-yl were synthesised. Their biological activity against wood-destroying fungi Serpula lacrymans, Coniophora puteana and Trametes versicolor was tested by the impregnated filter paper method. S. lacrymans occurred as the most sensitive fungus (from the 3 fungi) in the presence of triazines. Triazines having three imidazol or three 4,5-diphenylimidazol groups were a slightly more effective than others. However, their efficacy in comparison with the commercial fungicides Tebuconazole and IPBC was insufficient.
\end{abstract}

Keywords: 1,3,5-triazines, synthesis, wood-destroying fungi, screening test, growth inhibition

\section{Introduction}

In present, coming out from healthy and environmental demands for wood preservatives effective against rooting fungi and moulds (Biocidal Product Directive 98/8/EC), it is limited using of compounds on the basis of heavy metals (copper, chromium, arsenic, organotin, organocopper, etc.). In various commercial products are used mainly boric compounds, triazoles, benzimidazoles, isotiazolones, sulfamides, carbamates, and quarternary ammonium compounds (Reinprecht 2008). For future interesting could be also other organic compounds with biological efficiency, e.g. triazines.

Symmetrical triazines (s-triazines or 1,3,5-triazines) are larger class of compounds exploiting in many applications most of them due to their biological properties (von Angerer 2004, Bartholomew 1995, Afonso et al. 2006, Milata et al. 2001). Most of them are prepared from 2,4,6-trichloroderivative known as cyanuric chloride (Blotny 2006). Synthesis of trissubstituted triazines by easy leaving groups such as (benz)azoles (pyrazol-1-yl, 3,5-dimethylpyrazol-1-yl, 4-adamantylpyrazol-1-yl, imidazol-1-yl, 2-methylimidazol-1-yl,2-phenylimidazol-1-yl,2-adamantylimidazol-1-yl, 1,2,4-triazol-1-yl, benzimidazol-1-yl, 2-methylbenzimidazol-1-yl, 2-phenylbenzimidazol1-yl, 2-adamantylbenzimidazol-1-yl，2,5,6-trimethylbenzimidazol-1-yl) has been firstly described by Milata et al. (2001). This last type of triazines has been exploited for preparation of complexes with interesting properties (Carrión et al. 2003, Guerrero et al. 2004). Triazines bearing 1-benzimidazolyl substituents are described as compounds with fungicide and antitumor efficacy (Kawashima et al. 1999, Shibata et al. 2000). In a practice it is a very important also the stability of pesticides. Developments in the mechanisms of the direct photosensitized and photocatalyzed photodegradation and of photochemically generated hydroxyl radical-based degradation of triazine-based pesticides were reviewed by Canle et al. (2005). Dankwardt and Hock (2001) described the application of immunochemical methods for the investigation of non-extractable (bound) residues created from triazines.

The aim of our work was to synthesise symmetrical triazines with various heterocycle groups and test their activity against wood-destroying fungi by the method of impregnated filter papers.

\section{Results and discussion}

The basic physico-chemical properties of synthesised 1,3,5-triazines No. $\mathbf{1 - 8}$ are in Table 1.

Evaluation of the antifungal efficacy of the 1,3,5triazines and the commercial fungicides was carried out on the basis of:

- the growth inhibition index on malt-agar soils $\left(\mathrm{I}_{\mathrm{S}}\right)$; it was determined between the border of inoculate and the border of filter paper in the first days of test, it means to the moment when the inhibiting zone to control papers was ap- 
Tab. 1. Physico-chemical properties of the 1,3,5-triazines No. 1-8.

\begin{tabular}{|c|c|c|c|c|c|c|c|}
\hline \multirow[t]{2}{*}{ No. } & \multirow{2}{*}{$\begin{array}{l}\text { Mol. Formula } \\
\text { M.w. }\end{array}$} & \multirow[t]{2}{*}{ Formula } & \multirow{2}{*}{$\begin{array}{l}\text { M.p. } /{ }^{\circ} \mathrm{C} \\
\text { Yield/ } / \%\end{array}$} & \multicolumn{3}{|c|}{$\begin{array}{l}\text { Elemental analysis } \\
\text { (calculated/found) }\end{array}$} & \multirow{2}{*}{$\begin{array}{c}\mathrm{R}_{\mathrm{f}}^{\mathrm{a}} \\
\mathbf{M}^{+\cdot}(\text { rel. intensity })\end{array}$} \\
\hline & & & & $\% \mathrm{C}$ & $\% \mathrm{H}$ & $\% \mathrm{~N}$ & \\
\hline \multirow[t]{2}{*}{1} & $\mathrm{C}_{21} \mathrm{H}_{12} \mathrm{~N}_{12}$ & & $>320$ & 58.33 & 2.80 & 38.87 & 0.12 \\
\hline & 432.41 & & 76.8 & 58.22 & 2.81 & 38.97 & $432(96)$ \\
\hline \multirow[t]{2}{*}{2} & $\mathrm{C}_{12} \mathrm{H}_{9} \mathrm{~N}_{9}$ & & $259-261$ & 51.61 & 3.25 & 45.14 & $0.16 ; 0.51(1: 1)$ \\
\hline & 279.27 & & 54.8 & 50.07 & 4.085 & 42.07 & $279(100)$ \\
\hline \multirow[t]{2}{*}{3} & $\mathrm{C}_{12} \mathrm{H}_{9} \mathrm{~N}_{9}$ & & $240-243$ & 51.61 & 3.25 & 45.14 & 0.30 \\
\hline & 279.27 & & 75.0 & 51.69 & 3.49 & 44.82 & $279(95)$ \\
\hline \multirow[t]{2}{*}{4} & $\mathrm{C}_{18} \mathrm{H}_{21} \mathrm{~N}_{9}$ & & $241-244$ & 59.49 & 5.82 & 34.69 & 0.71 \\
\hline & 363.43 & & 29.4 & 59.55 & 5.92 & 34.29 & $363(65), 95(100)$ \\
\hline \multirow[t]{2}{*}{5} & $\mathrm{C}_{48} \mathrm{H}_{33} \mathrm{~N}_{9}$ & & $>320$ & 78.35 & 4.52 & 17.13 & 0.73 \\
\hline & 735.86 & & 86.2 & 78.49 & 4.49 & 17.02 & $735.86(100)$ \\
\hline \multirow[t]{2}{*}{6} & $\mathrm{C}_{25} \mathrm{H}_{15} \mathrm{~N}_{9}$ & & $364-366$ & 67.13 & 3.52 & 29.35 & 0.73 \\
\hline & 429.45 & & 81.9 & 65.74 & 3.731 & 28.50 & $429.1(100)$ \\
\hline \multirow[t]{2}{*}{7} & $\mathrm{C}_{27} \mathrm{H}_{21} \mathrm{~N}_{9} \cdot 2 \mathrm{H}_{2} \mathrm{O}$ & & $194-195$ & 63.89 & 4.96 & 24.84 & 0.48 \\
\hline & 471.53 & & 58.3 & 64.25 & 4.738 & 24.50 & $471.3(100)$ \\
\hline \multirow[t]{2}{*}{8} & $\mathrm{C}_{42} \mathrm{H}_{27} \mathrm{~N}_{9}$ & & $149-151$ & 76.70 & 4.14 & 19.17 & 0.66 \\
\hline & 657.74 & & 56.7 & 76.76 & 4.20 & 19.05 & $657(100)$ \\
\hline
\end{tabular}

${ }^{\mathrm{a}} \mathrm{In}_{\mathrm{CHCl}} / \mathrm{MeOH}=100: 1$ (retardation factor $-\mathrm{R}_{\mathrm{f}}, \mathrm{M}^{+} \cdot-$ molecular ion). 
proximately $0 \mathrm{~mm}(S$. lacrymans $=4$ days, $C$. puteana $=4$ days, $T$. versicolor $=3$ days)

$$
\mathrm{I}_{\text {Soil }}=\left(\mathrm{Iz}_{\mathrm{T}}-\mathrm{Iz}_{\mathrm{C}}\right) /\left(20-\mathrm{Iz}_{\mathrm{C}}\right) \times 100[\%]
$$

where: $\mathrm{Iz}_{\mathrm{T}}=$ Inhibiting zone to tested compound $[\mathrm{mm}], \mathrm{Iz}_{\mathrm{C}}=$ Inhibiting zone to control $[\mathrm{mm}], 20=$ $20[\mathrm{~mm}]$.

- the growth inhibition index on impregnated filter papers $\left(\mathrm{I}_{\mathrm{P}}\right)$; it was determined subsequently when the mycelia started to growth also on the poisoned papers

$$
\mathrm{I}_{\text {Paper }}=\left(\mathrm{L}_{\mathrm{c}}-\mathrm{L}_{\mathrm{T}}\right) / \mathrm{L}_{\mathrm{c}} \times 100[\%]
$$

where: $\mathrm{L}_{\mathrm{c}}=$ mycelium length acquisition on the control filter paper between two time intervals (e.g. $4^{\text {th }}-7^{\text {th }}$ day) $[\mathrm{mm}], \mathrm{L}_{\mathrm{T}}=$ mycelium length acquisition on the filter paper poisoned with tested compound between two time intervals of identical duration (e.g. $10^{\text {th }}-13^{\text {th }}$ day) $[\mathrm{mm}]$.

The growth inhibition indexes of 1,3,5-triazines, by which can be valued their efficiency against the most important wood-destroying fungi, are presented in Table 2. All the tested 1,3,5-triazines had an evidently lower efficacy against the wood-destroying fungi comparing with the commercial fungicides used at protection of wood and wooden materials. The dry-rot fungus Serpula lacrymans was relatively the most sensitive to tested 1,3,5-triazines, mainly against the triazines No. 2 (substituent = imidazol) and No. 5 (substituent $=4,5$-diphenylimidazol). As it is well known, the fungus $S$. lacrymans is a very dangerous on wooden elements in buildings, but on the other hand it belongs to the most sensitive fungi to various types of fungicides - e.g. to boric compounds (Reiprecht 2008, Bech-Andersen 1995), organotin compounds (Kizlink et al. 1996), etc. Efficacy of the triazines No.
2 and No. 5 to other used fungi Coniophora puteana and Trametes versicolor was evidently worse, but milder better than of other triazines.
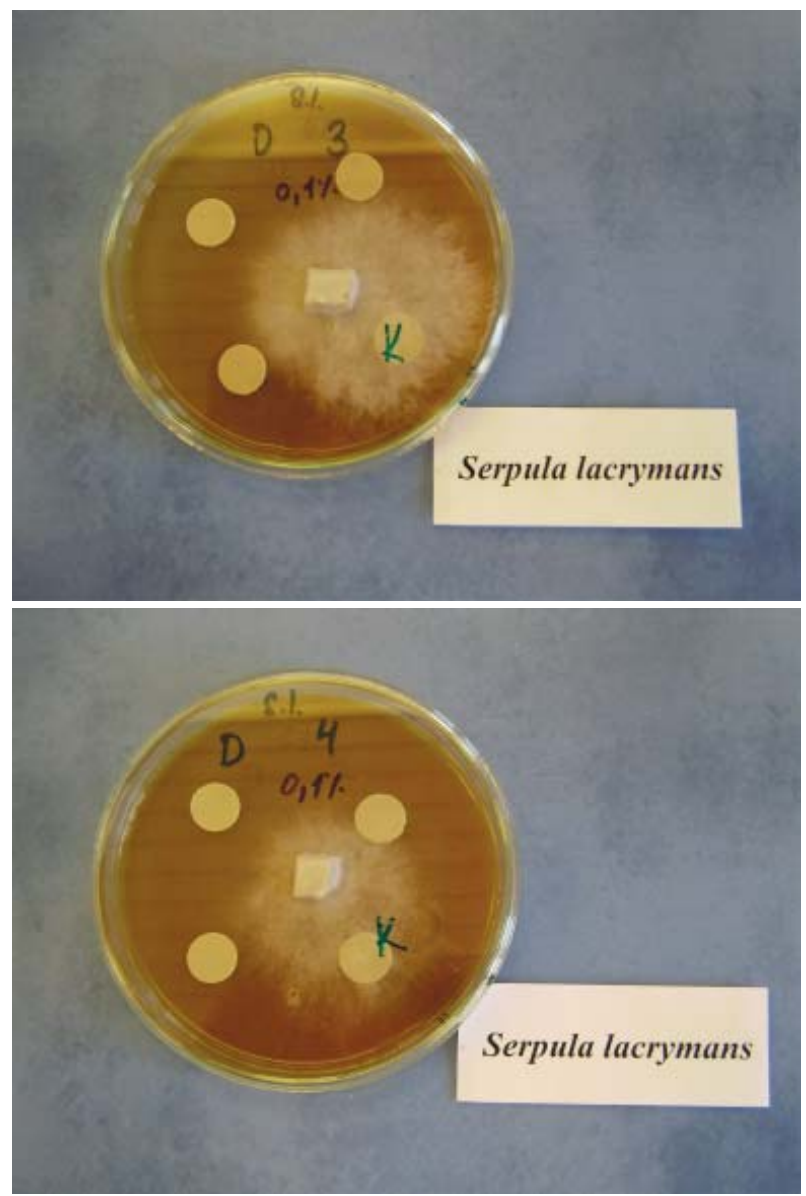

Fig. 1. Photos from screening tests of triazines 3 and 4 with S. lacrymans:

Triazine No. 3 (up), Triazine No. 4. (down). Note: $\mathrm{K}=$ control paper.

Tab. 2. Efficacy of 1,3,5-triazines against the wood-destroying fungi S. lacrymans, C. puteana and T. versicolor evaluated on the basis of the growth inhibition indexes $\mathrm{I}_{\text {Soil }}$ and $\mathrm{I}_{\text {Paper }}-\mathrm{using}$ the method of

\begin{tabular}{|c|c|c|c|c|c|c|}
\hline \multirow[t]{2}{*}{ COMPOUND $(\mathrm{c}=0.1 \%)$} & \multicolumn{3}{|c|}{$\mathrm{I}_{\text {Soil }}(\%)$} & \multicolumn{3}{|c|}{$\mathrm{I}_{\text {Paper }}(\%)$} \\
\hline & lacrymans & C. puteana & T. versicolor & S. lacrymans & C. puteana & T. versicolor \\
\hline \multicolumn{7}{|l|}{ No. $X$-1,3,5-triazine } \\
\hline 1. tris(benzotriazol-1/2-yl)- & 17 & 15 & 10 & 65 & 45 & 20 \\
\hline 2. tris(imidazol-1-yl)- & 30 & 24 & 15 & 90 & 55 & 40 \\
\hline 3. tris(pyrazolyl-1-yl)- & 22 & 17 & 10 & 80 & 50 & 30 \\
\hline 4. tris(3,5-dimethylpyrazolyl-1-yl)- & 24 & 20 & 10 & 85 & 45 & 25 \\
\hline 5. tris(4,5-diphenylimidazol-1-yl)- & 30 & 20 & 15 & 90 & 55 & 35 \\
\hline 6. tris(benzimidazolyl-1-yl)- & 20 & 17 & 8 & 60 & 55 & 20 \\
\hline 7. tris(2-methylbenzimidazolyl-1-yl)- & -20 & 11 & 13 & 85 & 40 & 20 \\
\hline 8. tris(2-phenylbenzimidazolyl-1-yl)- & )- 17 & 8 & 8 & 85 & 35 & 20 \\
\hline \multicolumn{7}{|l|}{ Commercial fungicides } \\
\hline Tebuconazole & 97 & 85 & 95 & 100 & 100 & 100 \\
\hline IPBC & 68 & 42 & 37 & 100 & 100 & 78 \\
\hline
\end{tabular}
impregnated filter papers. 


\section{Experimental}

General procedure for preparation of the symmetrical 1,3,5-triazines No. 1-8:

To $0.834 \mathrm{~g}$ (33 mmol, $95 \%$ ) of sodium hydride in dry THF - tetrahydrofurane $(60 \mathrm{~mL})$ is added under stirring in small portions $30 \mathrm{mmol}$ of the appropriate N-H-(benz)azole. When the effervescence is damped, the mixture is refluxed for 1 hour. Then is added dropwise solution of $1.844 \mathrm{~g}(10 \mathrm{mmol})$ 2,4,6-trichloro-1,3,5-triazine (cyanuric chloride) dissolved in dry THF $(20 \mathrm{~mL})$ and reaction is monitored using TLC. After finishing of the reaction the solvent is evaporated on rotavapour to dryness and water is added carefully (rests of sodium hydride, $50 \mathrm{~mL}$ ). The product is separated, purified and recrystallized from appropriate solvent. To remove the rests of solvents the vacuum drying (2 days at $95^{\circ} \mathrm{C}$ ) is required.

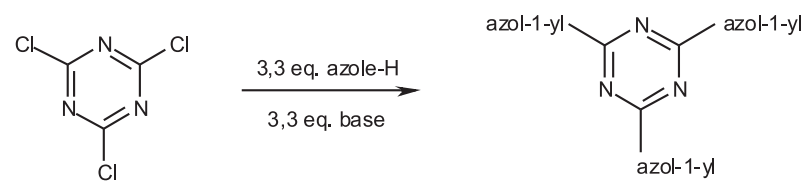

Fig. 2.

- tris(benzotriazol-1/2-yl)-1,3,5-triazine (1),

- tris(imidazol-1-yl)-1,3,5-triazine (2),

- tris(pyrazolyl-1-yl)-1,3,5-triazine (3),

- tris(3,5-dimethylpyrazolyl-1-yl)-1,3,5-triazine (4),

- tris(4,5-diphenylimidazol-1-yl)-1,3,5-triazine (5),

- tris(benzimidazolyl-1-yl)-1,3,5-triazine (6),

- tris(2-methylbenzimidazolyl-1-yl)-1,3,5-triazine (7),

- tris(2-phenylbenzimidazolyl-1-yl)-1,3,5-triazine (8).

The melting points of these 1,3,5-triazines were determined with a hot-stage microscope and are uncorrected. The $R_{f}$ values were measured and reaction were monitored on TLC aluminium sheets of silica gel Merck $60 \mathrm{~F}_{254}$ (layer thickness $0.2 \mathrm{~mm}$ ) with the mixture chloroform - methanol 10:1 as the eluent. Column chromatography was performed on silica gel Merck 60 (70-230 mesh), TLC on glass sheets of silica gel SDS $60 \mathrm{~F}_{254}$ (layer thickness $2 \mathrm{~mm}$ ), both using the same eluent $\left(\mathrm{CHCl}_{3} / \mathrm{MeOH}=100: 1\right)$. MS spectra were obtained with a Shimadzu QP-5000 and VG AUTOSPEC spectrometer (electron impact or FAB, 60-70 eV). ${ }^{1} \mathrm{H}$ NMR and ${ }^{13} \mathrm{C}$ NMR spectra were reported by Milata et al. (2001).

Imidazole, pyrazole, 3,5-dimethylpyrazole (Janssen Chimica), benzimidazole (EGA Chemie), 2-methylbenzimidazole (Fluka), 2-phenylbenzimidazole (Lancaster), benzotriazole (Lachema) are commercial products. 4,5-diphenylimidazole has been prepared according to Radziszewski (Bratulescu 2009).

\section{Screening efficacy test of symmetrical 1,3,5-triazines against wood-destroying fungi}

The antifungal activity of eight symmetrical 1,3,5triazines (tab. 1), and also of two comparative fungicides used in a practice: Tebuconazole ( $\alpha$-tertbutyl- $\alpha$ /4-chlorophenylethyl/1- $H$-1,2,4-triazole1-ethanol), and IPBC (3-iodo-2-propynyl- $N$-butylcarbamate), was determined by the method of impregnated filter papers (Reinprecht et al. 2003), against the following wood-destroying fungi (with collection numbers):

- Serpula lacrymans (Wulfen) J. Schröt, strain 6, (Štátny drevársky výskumný ústav Bratislava, Lamačská cesta 3, SK-84104 Bratislava), (brownrot fungus),

- Coniophora puteana (Schumacher ex Freis) Karsten, strain BAM Ebw. 15, (Bundesanstalt für Materialforschung und -prüfung, D-12205 Berlin), (brown-rot fungus),

- Trametes versicolor (Linnaeus ex Freis) Pilat, strain CTB 863 A, (Centre Technique du Bois et de l' Ameublement, 10 Avenue de Saint-Mandé, F-75012 Paris), (white-rot fungus).

Mycological tests were developed in sterile conditions in Petri dishes with a diameter of $100 \mathrm{~mm}$ filled with an approximately $3-4 \mathrm{~mm}$ thick solid layer of $3 \%$ malt-agar soil, at the incubating temperature of $22 \pm 1{ }^{\circ} \mathrm{C}$, during 14 days. Firstly, in the central point of each Petri dish was deposit on the malt-agar soil a fungal inoculate $5 \times 5 \mathrm{~mm}$, and then in a distance of $20 \mathrm{~mm}$ from the border of inoculate were deposit 4 rings (3 poisoned and 1 control) of filter paper Whatman 3CHR with a diameter of $14 \mathrm{~mm}$. The poisoned filter papers were impregnated with $0.1 \%$ solution of the tested compound, and the control ones only with the solvent $N, N$-dimethylformamide. The antifungal efficacy of each tested compound against the selected fungus was determined on 9 poisoned papers in 3 Petri dishes.

\section{Conclusions}

The aim of our work was the preparation and testing of selected substituted 1,3,5-triazines, which would be useful in the preservation of wood, because some of known organic fungicides are nowadays put out from the technical using (mercaptobenzthiazoles, thiobenzthiazoles, etc.). The antifungal efficacy of these heterocyclic compounds against wood-destroying fungi Serpula lacrymans, Coniophora puteana and Trametes versicolor occurred, however in comparison to commercial fungicides as IPBC or Tebuconazole it was evidently lower or minimal. The first step of 
synthesis and testing against wood-destroying fungi of selected triazines was here done. Some of these heterocyclic compounds would be maybe useful in the other branch of fungicides, e.g. in the veterinary or even human medicine.

\section{Acknowledgements}

The authors are grateful to the Slovak Grant Agency (Project 01/0660/11 and Project 1/0574/12), and the Slovak Research and Development Agency (APVV-0339. 10, APVV-0038-11) for financial support of this scientific work.

\section{References}

Afonso CAM, Lourenço NMT, de Rosatella A (2006) Molecules 11: 81.

von Angerer S (2004) Product Subclass 3: 1,3,5-Triazines and Phosphorus Analogues, in Science of Synthesis, Vol. 17.2.3, vol. ed. Weinreb S.M., Georg Thieme Verlag, Stuttgart, p. 449-581.

Bartholomew D (1995) 1,3,5-Triazines in Comprehensive Heterocyclic Chemistry II - Review of Literature 1982-1995, Vol. 6, Section 6.12, Pergamon Press, Oxford.

Bech-Andersen J (1995) The dry rot fungus and other fungi in houses. Hussvamp Laboratoriet ApS, Holte - Denmark, 139.
Blotny G (2006) Tetrahedron 62: 9507.

Bratulescu G (2009) Synth. 14: 2319.

Canle LM, Fernández MI, Santaballa JA (2005) J. Phys. Org. Chem.18: 148.

Carrión CM, Guerrero A, Jalón FA, Manzano BR, de la Hoz A, Claramunt RM, Milata V, Elguero J (2003) Inorg. Chem. 42: 885 .

Dankwardt A, Hock B (2001) Chemosphere 45: 523.

Guerrero A, Jalón FA, Manzano BR, Rodríguez A, Claramunt RM, Cornago P, Milata V, Elguero J (2004) Eur. J. Inorg. Chem. 549.

Kawashima S, Matsuno T, Zaguchi S, Watanabe T, Inaba M (1999) PCP Int. Appl., WO 9905138 A1, $4^{\text {th }}$ February 1999 (Chem. Abstr. 1999, 130, 153673).

Kizlink J, Fargašová A, Reinprecht L (1996) Biologia 51: 671.

Milata V, Claramunt RM, Cabildo P, Santa MMD, Cornago P, Infantes L, Cano FH, Elguero J (2011) Heterocycles 55: 905.

Reinprecht L, Kizlink J, Švajlenová O (2003) Acta Fac. Rer. Nat. Univ. Ostr. Biol. Ekol., Czech Republic, 210: 29.

Reinprecht L (2008) Ochrana dreva. (Wood protection). Textbook, Technical University Zvolen, 453 p. (ISBN 978-80-228-1863-6).

Shibata M, Kawai K, Makihara Y, Yonekura N, Kawashima T, Sakai J, Marumatsu N (2000) PTC Int. Appl., WO 2000029404 A1, 25 May 2000 (Chem. Abstr. 2000, 132, 347593). 